\title{
Measuring regional cohesion effects of large-scale transport infrastructure investments: an accessibility approach
}

\author{
Elena López Suárez \\ TRANSyT-UPM, Centre for Transport Research, Universidad Politécnica de Madrid \\ ETSI Caminos, Canales y Puertos, av/ Profesor Aranguren, s/n \\ 28040 Madrid \\ E-mail: elopez@caminos.upm.es
}

\begin{abstract}
Cohesion is considered one of the main policy goals both at a EU an national level. However, there is currently a lack of a common approach to measure cohesion effects of large-scale transport infrastructure investments.

Accessibility indicators have an unexploited potential in transportation assessment methodologies. Accessibility is considered an added value of locations, which represents one of the elements contributing to a region's welfare. Therefore, spatial distribution of accessibility may be used as a proxy to assess regional cohesion.

This paper suggests an approach consisting in measuring changes in the spatial distribution of four different accessibility indicators, computed and mapped using a GIS support. Cohesion is subsequently measured calculating a set of inequality indices of the resulting accessibility distribution. It is possible then to assess whether disparities in regional accessibility are increased or reduced after the implementation of a new transport infrastructure.

This approach is tested assessing regional cohesion effects of road and rail network developments in Spain in the period 1992-2004. Comparing the results obtained with accessibility indicators and inequality indices allows identifying the main critical factors and sources of bias. The conclusion is that for the rode mode, cohesion has improved, while regional disparities have increased for the rail mode.
\end{abstract}

Keywords : regional cohesion, accessibility indicators, transport infrastructure investments 


\section{Introduction}

National transport infrastructure assessment methodologies agree on the treatment of direct impacts: most of them follow either a cost-benefit analysis (CBA) or a core CBA-approach complemented by a multicriteria analysis (MCA) (Hayashi and Morisugi, 2000). These appraisal methods may be adequate for limited-scope individual projects, but they have certain limitations for the assessment of transport infrastructure plans or programmes. Recent studies have shown interesting attempts to develop a more strategic approach, covering a wider range of impacts (Beuthe, 2002).

Infrastructure provision is considered a key factor in achieving territorial cohesion (EC, 2004), and deficiencies in accessibility are seen as an obstacle for economic development. However, the treatment of distributive effects of transport infrastructure is uneven and scarce (Grant-Muller et al, 2001). In addition, some authors argue that certain investments may lead to increasing rather than reducing regional disparities (Martín et al, 2004; Vickerman et al, 1999).

Distributive effects -often referred to as equity or cohesion effects - are one of these impacts. In this research area, accessibility indicators have an important role to play. Recent development of GIS techniques have turned accessibility indicators into useful tools to evaluate some of the so-called "wider" impacts.

This paper suggests an accessibility approach $\mathfrak{b}$ assess distributive effects of transport plans or programmes. The approach consists in taking changes in the equality of the spatial distribution of accessibility indicators as a proxy for measuring cohesion impacts. However, several factors may affect the conclusions taken, mainly the selection of the accessibility indicator and inequality indices, special features of each transport mode, or the spatial scale of the study.

All the above issues are investigated in this paper. First, section 2 reviews the literature on the treatment of cohesion and accessibility impacts of infrastructure investments. Later, section 3 suggests an accessibility approach to measure infrastructure cohesion impacts. This approach is then tested in Section 4, assessing cohesion effects of large-scale surface transport infrastructure investments, occurred in Spain in the period 1992-2004. Finally, section 5 includes the main conclusions taken.

\section{The treatment of accessibility and cohesion effects of infrastructure projects}

\subsection{The relationship between accessibility and cohesion}

There are many possible definitions of accessibility. The definition that best fits with this study refers to accessibility as a feature that "describes the location of an area with respect to opportunities, activities or resources that exist in other areas or in the same area" (Wegener et al, 2000).

In land-use/transport planning, accessibility is considered as a means to economic activity and social cohesion, rather than a desirable good by itself (Vickerman et al, 1999). For the individual, accessibility represents an aspect of freedom of action, which is of fundamental importance both economically and socially (Simmonds, 1998). Hence, accessibility is considered an added value of a location and an important factor of quality of life (Schürmann et al, 1997), while lack of accessibility is undesirable because it is considered partly responsible for lagging economic development. However, the regional economic development implications of transportation 
improvements are highly complex and difficult to determine methodologically (Bökerman et al, 1997).

Despite this debate on the effects of accessibility and economic development, spatial distribution of accessibility is one of the output variables used to measure the existing disparities among regions. In fact, it is one out of a long list selected by the EU (EC, 2004), in their periodical Cohesion Reports, which includes macroeconomic indicators as GDP per capita, employment levels or R\&D investments. In this sense, "equality of access to "services of general economic interest" is a key condition for territorial cohesion (EC, 2004). Special interest is placed in regions with geographical handicaps characterized by problems of accessibility and integration with the rest of the EU. Accessibility is thus a key factor in the achievement of the cohesion objective of the EU: to provide a fair distribution of accessibility to all its regions and to reduce existing disparities in accessibility between them (Schürmann et al, 1997).

In this context, accessibility indicators are an important input to an equity assessment, although its potential has not been so far fully exploited (Simmonds, 1998). Since the first definitions of accessibility were developed in the early 50's, there has been a continuous evolution of the theoretical foundations of accessibility indicators, resulting in a wide range of available formulations (see Geurs and Ritsema Van Eck (2001); Bruinsma and Rietveld, (1998). However, refinements of accessibility indicators are only useful if they contribute to improve our understanding of why some regions grow and some decline (Vickerman et al, 1999).

Activity-based accessibility measures, focused on the distribution of activities in space, ore often used in geographical studies but are not put to the same use in transport policy evaluation (Geurs and Ritsema van Eck , 2003). In the past, accessibility concepts have been widely reported within appraisal, but its use in the final assessment score has been quite limited, mainly because of concerns about double counting of effects (Beuthe, 2002).Recent research has identified the role and application of robust quantitative approaches, allowing accessibility measures to take a more central role within transport appraisal (Halden, 2003). A survey on the usability of different accessibility measures for evaluation purposes can be found in Geurs and van Wee (2004).

\subsection{Cohesion as a policy goal}

Cohesion is one of the main policy goals of the EU. The still un-ratified Treaty Establishing a Constitution for Europe (OJEU, 2004), includes "the promotion of economic, social and territorial cohesion" as one of the Union's objectives (article I-3). Moreover, cohesion is defined as one of the areas of shared competence between the Union and the Member States (Article I-14), and there is a complete Section devoted to cohesion (Section 3, Articles III-220 and the following). This Section states that: “(...) particular attention shall be paid to rural areas, areas affected by industrial transition, and regions which suffer from severe and permanent natural or demographic handicaps such as the northernmost regions with very low population density and island, crossborder and mountain regions (...)". Finally, (Art. II-96), "The Union recognises and respects access to services of general economic interest (...) in order to promote the social and territorial cohesion of the Union".

Another important institutional support to cohesion objectives comes from the European Spatial Development Perspective (ESDP) (EC, 1999). This policy document stresses that "spatial development policies can contribute in a decisive way to the achievement of the goal of territorial and social cohesion, in particular transport 
infrastructure investments in lagging regions". These ideas are coherent with the European Commision's position on the achievement of the cohesion objective. In particular, the Third Cohesion Report (EC, 2004) introduces the concept of territorial cohesion: “ (...) the objective is to help achieve a more balanced development by reducing existing disparities, avoiding territorial imbalances and by making both sectoral policies which have a spatial impact and regional policy more coherent".

The creation of the trans-European networks (TENs) is considered one of the essential EU policy instruments to achieve the cohesion goal. In this sense, the recently updated version of the Community Guidelines for the development of the TENs (EC, 2004a), states that the TENs must "contribute to strengthening economic and social cohesion".

Changing the scale to the national level, Spanish policy documents also include cohesion as a key policy goal, and investment in transport infrastructure as an essential instrument to achieve it. In particular, the recently published "Infrastructure and Transport Strategic Plan (PEIT)" for the period 2005-2020 (Ministry for Development, 2004), includes social and economic cohesion among the most relevant policy objectives. This policy goal is specifically cited in the PEIT, states that the development of the transport system should be aimed at "ensuring equity of accessibility conditions to the whole national territory".

\subsection{The treatment of cohesion effects in assessment methodologies}

The ESDP (EC, 1999) includes in the "to-do" list the "Introduction of territorial impact assessment as an instrument for spatial assessment of large infrastructure projects, especially in the transport sector" There is little concept of how the appraisal should handle this issue, even at the level of indicators or qualitative assessment (Mackie and Nellthorp, 2003).

The review carried out in subsection 2.2. confirms that infrastructure investment is considered a key policy instrument in achieving the cohesion goal both at EU and at a national scale. However, this concern has not been translated to the practice of evaluation, where cohesion is not usually included among the evaluation criteria of transport infrastructure assessment methodologies (Grant-Muller et al, 2001).

The complexities involved in the inclusion of equity as an evaluation criterion are not only methodological, but also related to value judgements on the weight to be assigned to the cohesion criterion. Therefore, planners have tended to approach distributional equity in a rather ad-hoc fashion. The classical approach consists in computing a set of statistical variables, (cohesion or inequality indices) in order to characterize the sample's dispersion. In addition, recent attempts include measuring equity exploiting GIS capabilities to visualize the spatial distribution of the variable under study, via an "equity mapping" approach (Talen, 1998),

In general terms, regional cohesion effects refers to territorial impacts of a given policy on the spatial distribution of a selected variable representing each region, e.g. GDP per capita. In the context of this paper, the policy corresponds to large-scale transport infrastructure investments, and the selected variable is regional accessibility. Thus, the objective is to assess if, as a result of the implementation of a new infrastructure, the existing regional disparities in accessibility are increased (polarisation effects. i.e. reduced cohesion) or reduced (equalisation effects, i.e. increased cohesion).

This paper suggests to measure equity impacts both graphically, using a GIS to draw accessibility maps, and quantitatively, via the calculation of a set of statistical variables characterizing the regional distribution of accessibility values. 


\section{Measuring cohesion effects: an accessibility approach}

\subsection{Selection of accessibility indicators}

As detailed in section 2.1., there is a multitude of available formulations to measure accessibility (see Geurs and Ritsema van Eck (2001) for a comprehensive survey).

To carry out this study, four different formulations of accessibility indicators have been selected. The four of them refer to different approaches to the concept of accessibility, hence they offer complementary information: some of them are more infrastructure-oriented, while others are more strongly influenced by the geographic position of each location. They are briefly described bellow.

\subsubsection{Location indicator}

This indicator calculates a weighted -by destination population- average travel time between each node and a choice of region's centroids, according to the following formulation:

$$
L_{i}=\frac{\sum_{j=1}^{n} I_{i j} \cdot P_{j}}{\sum_{j=1}^{n} P_{j}}
$$

where $\mathrm{L}_{\mathrm{i}}$ is the accessibility (location) of node $\mathrm{I}, \mathrm{I}_{\mathrm{ij}}$ is the impedance: travel time by the minimal route through the network between node $i$ and the centroid of region $j$ (in $\min$ ), and $\mathrm{P}_{\mathrm{j}}$ is region's $\mathrm{j}$ population.

The mass of each destination is used as a weight in order to value the importance of the minimal time routes (Gutiérrez and Urbano, 1996; Gutiérrez, 2001). The results obtained in each node strongly depend on its geographical position, showing clear coreperiphery patterns. Remote locations inevitably appear with low accessibility values, as a good provision of transport infrastructure is not enough to overcome the negative effects of a large geographical distance to the main activity centres.

This indicator has the advantage that its results are easily interpreted, as they are expressed in familiar units -travel times- and therefore changes in this indicator are usually used as a proxy for computing travel time savings. However, it has some limitations, mainly stemming from the fact that it does not discriminate between far and nearby destinations, therefore their values depend heavily on the selected sets of destinations, i.e. the arbitrary cut-of point of the $\mathrm{Pj}$ that determines which destinations are included.

\subsubsection{Gravity-based network efficiency indicator}

The fact that the results offered by indicators like the location one are heavily influenced by the geographic location of the nodes makes these measures unsuited for determining the transport infrastructure needs of each region. The formulation of the efficiency indicator neutralizes the effect of the geographic location, and allows making 
judgements on the relative "ease of access" -network efficiency- of each location (Guiterrez et al, 1998). Its formulation is as follows:

$$
E_{i}=\sum_{j=1}^{n} \frac{\frac{I_{i j}}{I I_{i j}} \cdot w_{i j}}{\sum_{j=1}^{n} w_{i j}}
$$

where $E_{i}$ is the network efficiency indicator, $I_{i j}$ is the "ideal impedance": expresses travel time between $i$ and $j$ "as the crow flies" or Euclidean distance (in min), $\mathrm{w}_{\mathrm{ij}}$ is a ratio between destination population and distance between $\mathrm{i}$ and $\mathrm{j}$, and the rest of the terms are already known.

This is a gravity-based accessibility indicator, as the importance of each relation i$j$ in the final calculation of the accessibility of mode i increases with destination's mass and decreases with the distance between $\mathrm{i}$ and $\mathrm{j}$.

This indicator gives important information on how efficient are the network connections from a given node, independently from its geographic situation: the closer the value is to 1 , the higher the accessibility the network provides to that node. Therefore, it may occur that a region which is peripheral according to the location indicator is highly accessible in terms of network efficiency.

\subsubsection{Population potential indicator}

The population potential is a gravity-based measure, adaptated from the standard approach of economic potential measurement following Hans en (1959), where GDP is replaced by population, as in Bruisma and Rietveld (1993), resulting as follows:

$$
\text { Pot }_{i}=\sum_{j=1}^{n} \frac{P_{j}}{I_{i j}^{a}}
$$

where Pot $_{\mathrm{i}}$ is the population potential of node $\mathrm{i}$, and a is a gravity parameter assumed to equal 1. This is the parameter value used most often in empirical studies: a higher value would over-weight relations over short distances and would also increase the problem of the measurement of the "internal accessibility" (Bruinsma and Rietveld, 1998, Gutiérrez, 2001). The rest of the terms are already known.

This indicator gives an aggregate measure of a region's market area, resulting in a deceptively reduction in potential as we move away from the centre (Vickerman et al, 1999). Multimodal potential accessibility indicators (computing a multimodal travel time) have shown the highest explanatory value in the resulting economic development of each region (Schürmann et al, 1997).

\subsubsection{Daily accessibility indicator}

This indicator is based on the concept of a fixed budget for travel, usually set up between 3 and $5 \mathrm{~h}$, so that it is possible to travel to a certain city, conduct business there and return within the day (Lutter et al, 1992). This is the reason why it is called "daily" accessibility indicator. 
In this study, the indicator calculates, from each node, the number of inhabitants that can be reached in less than 4 hours:

$$
D_{i}=\sum_{j=1}^{n} P_{j} \cdot \theta_{i j}
$$

where $D_{i}$ is daily accessibility of node $I, T_{i j}=1$ if $I_{i j}<4$ hours, and 0 otherwise, and the rest of the terms are already known.

This indicator can be viewed as an extreme case of a potential market indicator because the distance-decay function takes the discontinuous form of all-or-nothing depending on the threshold of travel time considered (Gutiérrez, 2001). Although it has been widely used in studies at a EU scale (Schürmann et a 19971, Martín et al, 2004), the arbitrary selection of the maximum travel time requires caution when interpreting differences in accessibility values after the implementation of a new infrastructure.

\subsection{Methodological concepts: how to measure cohesion?}

Cohesion (or inequality) indices are macro analytical indicators combining the accessibility values of individual regions into one single measure of spatial concentration or dispersion of accessibility (see Schürmann et al, 1997, for a review of existing formulations ).

From the large list of available indices, five of them have been selected. For explanatory reasons, they have been classified into "static" and "dynamic" indices, indicating whether they allow measuring the sample's equity in any given moment, or they are only applicable for inter-temporal comparisons, respectively. However, changes in any static index result in a dynamic index.

Static analysis helps in identifying the importance of the choice of the accessibility indicator and the specific characteristics of each mode. Dynamic analysis allows assessing cohesion impacts of infrastructure investments.

\subsection{1. "Static" indices}

Two indices have been selected: the variation coefficient and the Gini index. They are briefly described as:

- Variation coefficient: it is defined as the standard deviation of the distribution expressed in percent of their mean. It ranges between 0 (no variation) and 100 (extreme polarisation).

- Gini index: it measures double the area between the accumulated distribution of sorted indicator values (i.e. Lorenz curve) and the straight line representing an equal distribution. It takes values between 0 (equal distribution) and 1 (extreme polarisation).

\subsection{2. "Dynamic indices"}

For this study, a selection of three indices composes this group of measures. Their description is as follows: 
- Spearman's rank correlation coefficient: it compares two rank orders of values by decreasing or increasing accessibility. This coefficient is aimed at a dynamic analysis of accessibility, therefore not representing accessibility disparities for a specified moment in time. Its formulation is as follows:

$$
r=1-6 \cdot \sum \frac{d^{2}}{n \cdot\left(n^{2}-1\right)}
$$

where $r$ is the Spearman coefficient, $d$ is the difference in statistical rank of corresponding variables, and $\mathrm{n}$ is the number of observations. The coefficient takes values in the interval -1 and 1 . A correlation coefficient of 1 indicates that there has been no change in the rank order of regions, while a -1 value indicates that the rank order has been reversed.

- Correlation coefficient relative change vs. level : this indicator examines the relationship between the percentage change of an indicator and its magnitude by calculating the correlation coefficient between them. The sign of the coefficient determines if disparities increase -positive correlation coefficient- or are reduced - negative correlation coefficient (Bröcker et al, 2004).

- Correlation coefficient absolute change vs. level : the definition of this indicator is the same, except that absolute instead of relative change is considered 


\section{Case study: Spain, 1992-2004}

\subsection{Introduction}

The study assesses regional cohesion effects deriving from surface transport infrastructure investments (i.e. in road and rail modes), carried out in the period 19922004. In these twelve years, the high capacity road network was enlarged from near $6,000 \mathrm{~km}$ to $9,000 \mathrm{~km}$. For the rail mode, the HSR network was enlarged from near 450 $\mathrm{km}$ (Madrid-Seville HSR line) to $930 \mathrm{~km}$, with the opening of the HSR Madrid-Lleida.

The geographical area includes the Spanish territory in the Iberian Peninsula. It comprises 15 Autonomous Regions, each of them subdivided in provinces (equivalent to NUTS-3 divisions), which are finally divided into municipalities (NUTS-5), up to a final amount over 8,000. The output of the GIS modelling work consists therefore of a set of over 8,000 municipality's values of accessibility indicators. For operational reasons, the aforementioned values have been subsequently aggregated to obtain one single value for each of the 47 Iberian provinces (which will be called regions from now on), using population as the weighting variable.

Population is the selected variable to measure destination's attractiveness. Population of 2004 has been kept constant in the 1992 and 2004 analysis, in order to separate the effect stemming from infrastructure improvements from the one derived from population growth. The selected destination centres correspond to the centroids of the aforementioned 47 regions. In addition, centroids in Portugal and the three southern French regions have been included not as origin nodes but only as destination centres, at a more aggregated level (NUTS-2).

Using GIS software, load travel times were calculated based on average travel speeds depending on the road type. In addition to this travel times, calculations include time penalizations in roads crossing mountainous areas or large urban agglomerations. For the rail mode, calculations are more complex. The spatial separation between stations makes the modelled rail network unavoidably multimodal. Road is therefore the connecting mode to the nearest train station, where a penalization for the intermodal change is applied. Rail travel times have been obtained from the fastest train service, according to Thomas Cook travel times. Node impedances when changing from Iberian to UIC track gauge, and penalizations due to transfer times when travel time exceeds 4 hours complete rail travel time calculations.

\subsection{Accessibility results}

\subsubsection{Road mode}

Table 1 includes a summary of the regional accessibility results for the road mode, for the four accessibility indicators described in section 3.1. 
Table 1: Regional accessibility results. 1992, 2004, and change. Road mode

\begin{tabular}{|c|c|c|c|c|c|c|c|}
\hline & \multicolumn{3}{|c|}{1992} & \multicolumn{3}{|c|}{2004} & \multirow{2}{*}{ Change $^{\mathrm{h}}$} \\
\hline & $\operatorname{Min}^{\mathrm{e}}$ & Mean $^{1}$ & $\operatorname{Max}^{\mathrm{g}}$ & Min & Mean & $\operatorname{Max}$ & \\
\hline Location $^{\mathrm{a}}$ & 491 & 365 & 271 & 458 & 350 & 270 & 4.1 \\
\hline Network efficiency ${ }^{b}$ & 1.84 & 1.60 & 1.24 & 1.74 & 1.55 & 1.24 & 3.0 \\
\hline Population potential ${ }^{\mathrm{c}}$ & 89.876 & 134.639 & 397.602 & 98.476 & 139.349 & 404.788 & 3.5 \\
\hline Daily accessibility $^{\mathrm{d}}$ & 2.18 & 7.19 & 13.62 & 2.85 & 7.91 & 13.66 & 10.1 \\
\hline $\begin{array}{l}\text { a minutes } \\
\text { b adimensional ratio } \\
\text { c inhab/minutes x } 10^{3} \\
\text { d million inhab }\end{array}$ & & & $\begin{array}{l}{ }^{\mathrm{e}} \text { min } \\
{ }^{\mathrm{f}} \mathrm{mea} \\
{ }_{\mathrm{g}} \mathrm{ma} \\
{ }^{\mathrm{h}} \text { per }\end{array}$ & $\begin{array}{l}\text { Imum value } \\
\text { a value } \\
\text { imum value } \\
\text { entage chan }\end{array}$ & compar & to $1992 \mathrm{~s}$ & dation \\
\hline
\end{tabular}

Results show that perceived improvement rates vary according to the indicator chosen, ranging from a $3.0 \%$ in terms of the population potential indicator, to a $10.1 \%$ for the daily accessibility indicator. For example, in terms of the location indicator, which is the more easy to interpret, mean weighted average travel times are reduced from $365 \mathrm{~min}$ in 1992 to $350 \mathrm{~min}$ in 2004 (i.e. a $4.1 \%$ reduction).

As a result of the modelling work, a multitude of maps have been drawn, representing the four accessibility indicators, road and rail modes, and values corresponding to 1992, 2004 and \% change with respect to 1992 situation. This results in a total of $4 \times 2 \times 3=24$ maps. It is not possible to include all of them in this paper, so the choice has been to include the $4 \times 2=8$ maps showing percentage change.

Figures 1 to 4 map differences in road mode accessibility values between 1992 and 2004, in percentage change of 1992 values, for location, network efficiency, population potential and daily accessibility indicators, respectively. In all cases, the resulting overall pattern is similar: the northwest (Galicia regions) concentrates the higher percentage of change, with values above $10 \%$ in some cases. This is mainly due to the completion of the highway link from Galicia to Madrid. As Galicia suffered from deficient accessibility values in 1992, the concentration of higher relative gains in this area signals a reduction in accessibility disparities. The cohesion analysis included in section 4.3. will determine the reliability of this early statement.

In descending order, next regions with higher benefits concentrate in the southeast area (Murcia, eastern Andalucia), along with some inner locations where particular links have been built. Finally, Cataluña, Extremadura and northwest of Andalucia are the areas whit lower relative improvements. 
Figure 1. Changes in location accessibility indicator 1992-2004. Road mode

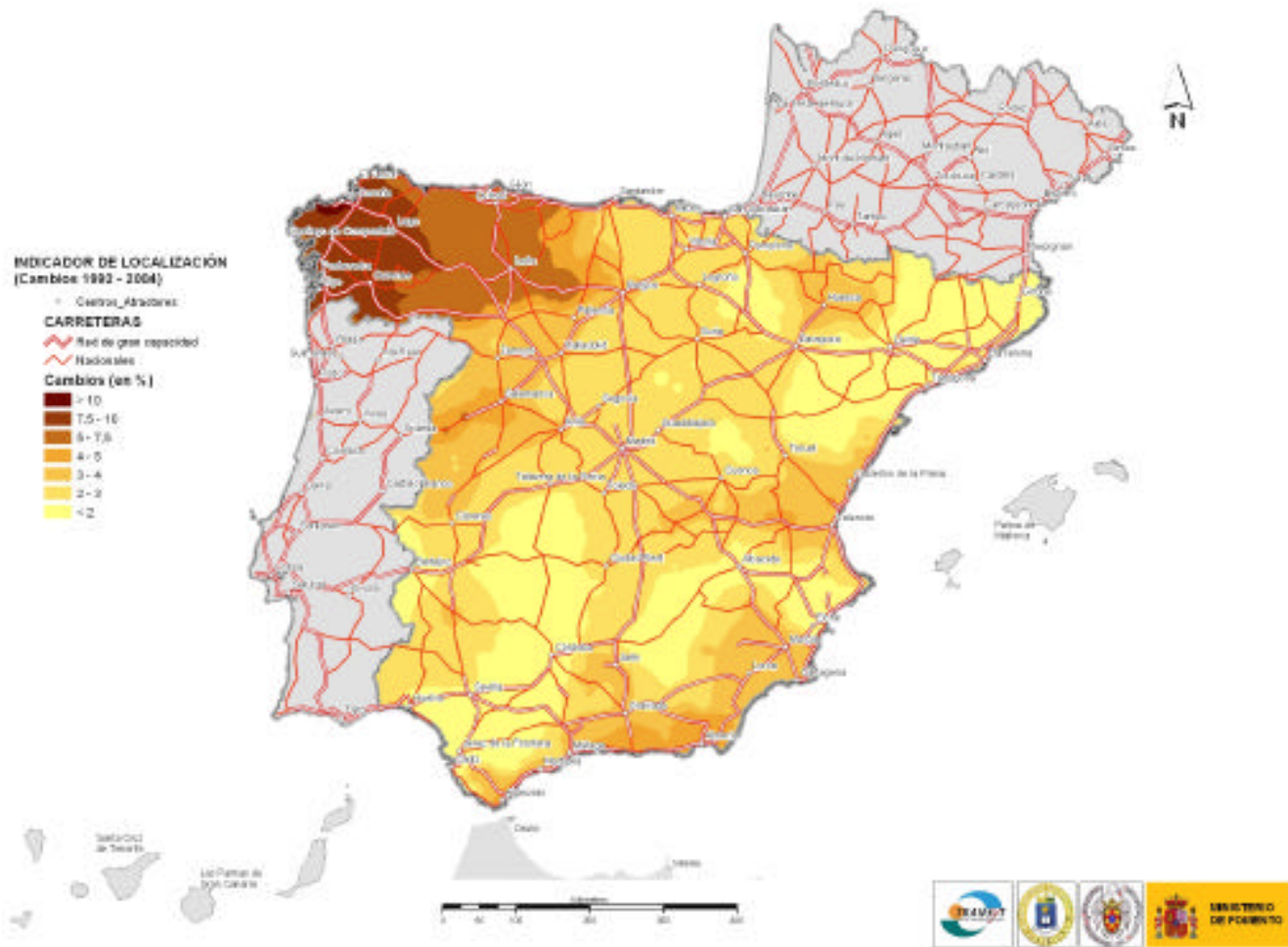

Figure 2. Changes in network efficiency accessibility indicator 1992-2004. Road mode

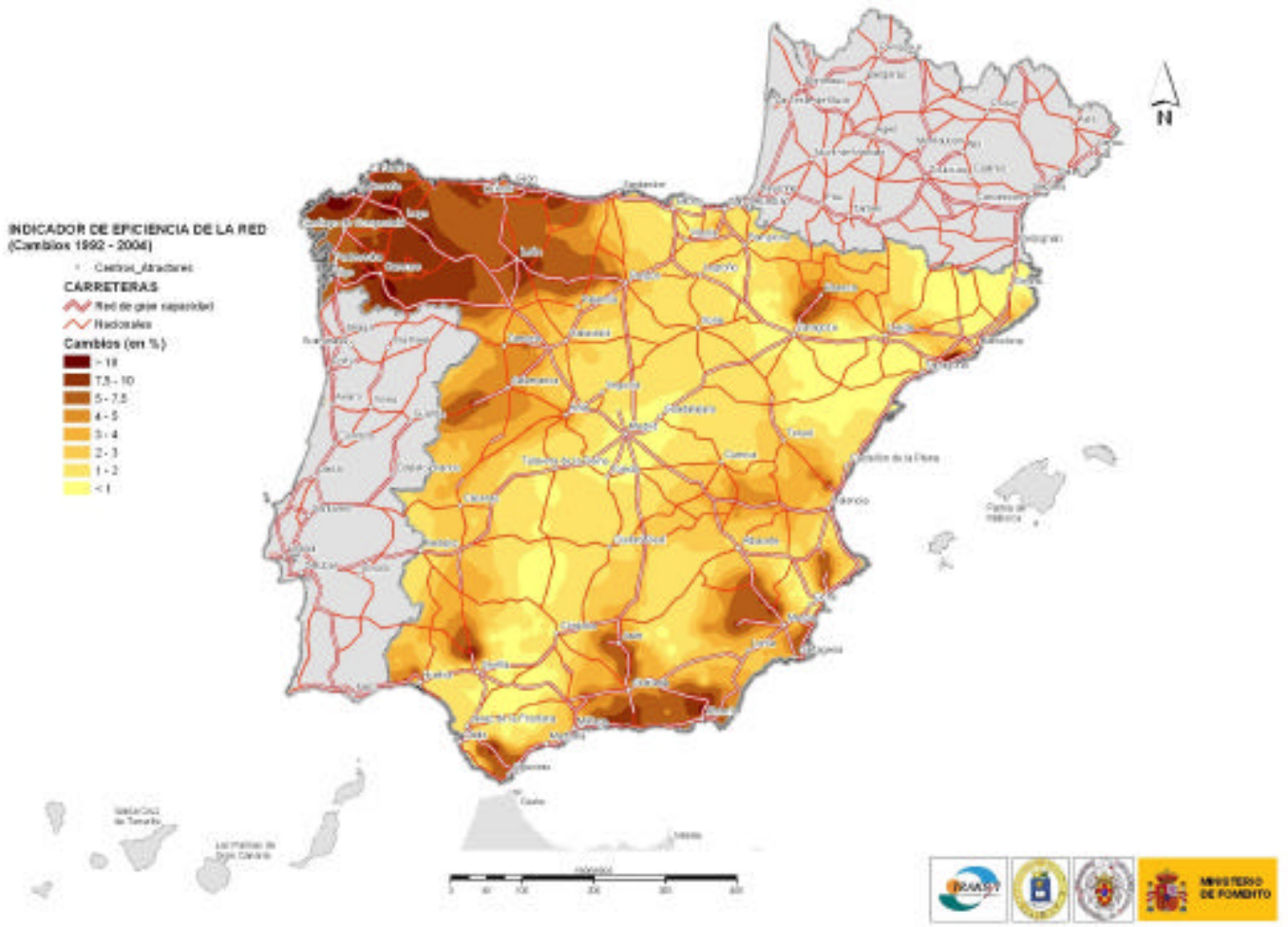


Figure 3. Changes in population potential accessibility indicator 1992-2004. Road mode

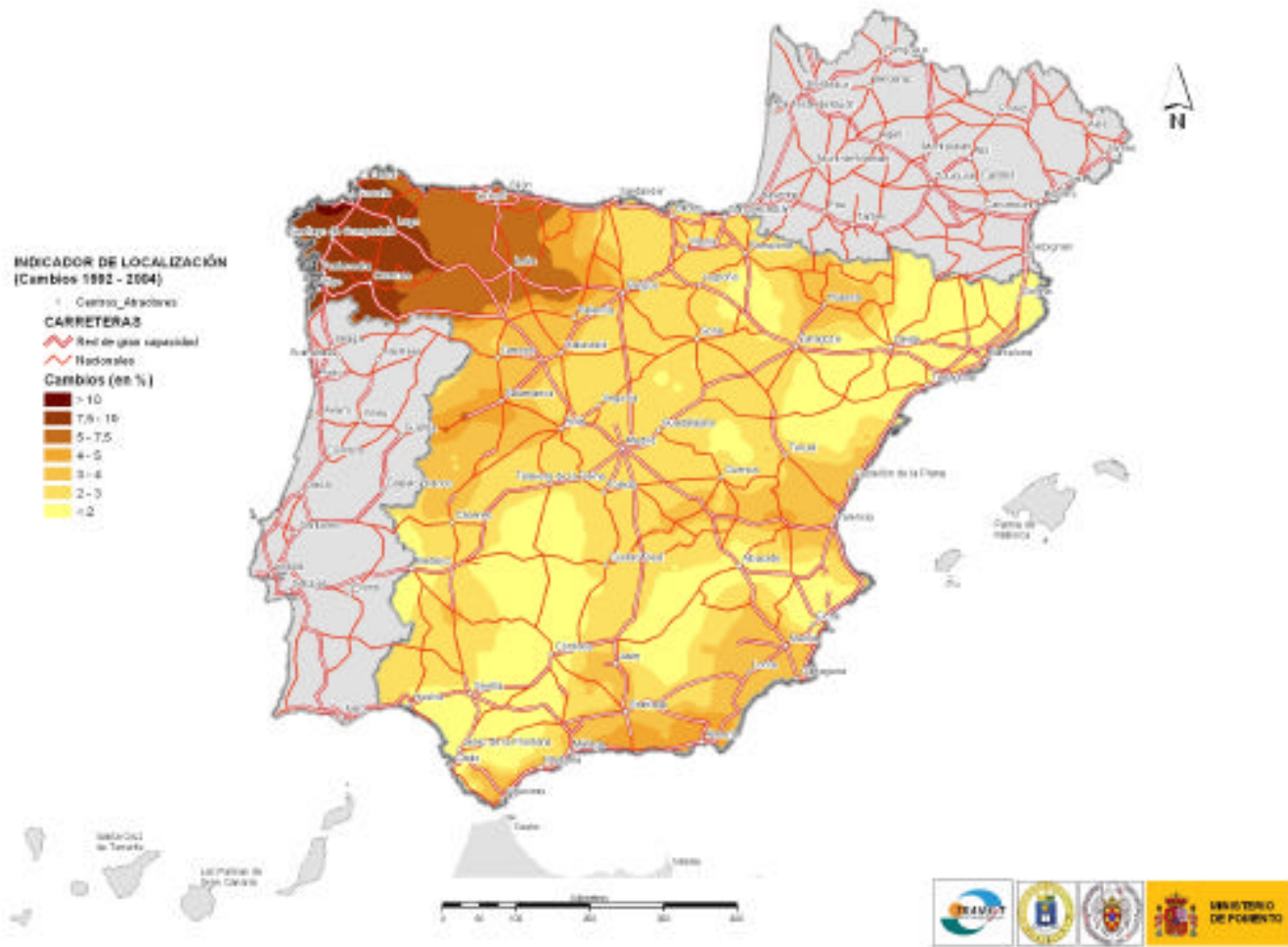

Figure 4. Changes in daily accessibility indicator 1992-2004. Road mode

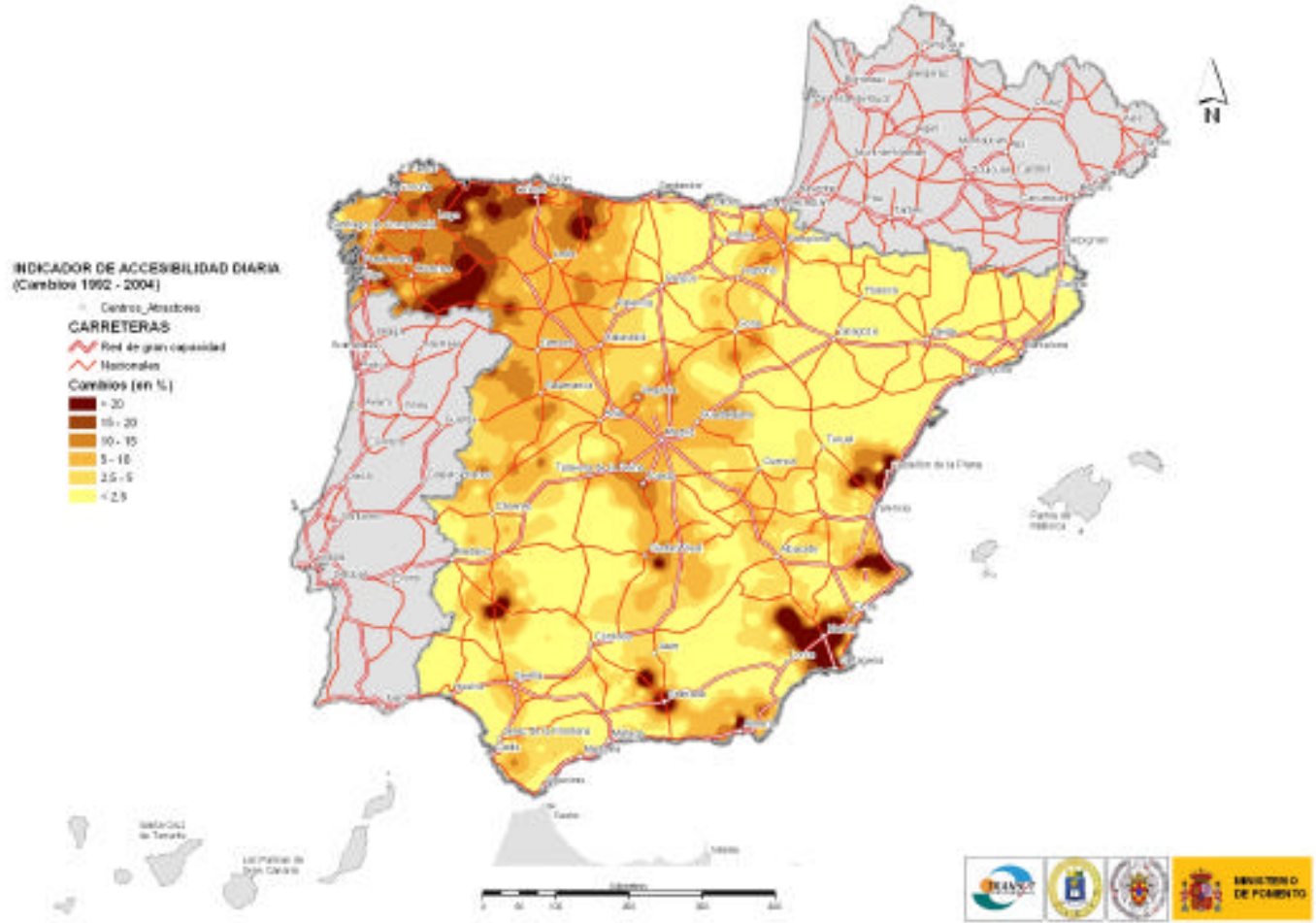




\subsubsection{Rail mode}

Table 2 includes a summary of the regional accessibility results for the rail mode.

Table 2: Regional accessibility results. 1992, 2004, and \% change. Rail mode

\begin{tabular}{|c|c|c|c|c|c|c|c|}
\hline & \multicolumn{3}{|c|}{1992} & \multicolumn{3}{|c|}{2004} & \multirow{2}{*}{ Change $^{\mathrm{h}}$} \\
\hline & $\operatorname{Min}^{e}$ & Mean $^{\mathrm{T}}$ & $\operatorname{Max}^{g}$ & Min & Mean & Max & \\
\hline Location $^{a}$ & 870 & 640 & 448 & 843 & 589 & 421 & 7.9 \\
\hline Network efficiency ${ }^{b}$ & 9.82 & 7.22 & 3.90 & 9.23 & 6.68 & 3.7 & 7.5 \\
\hline Population potential $^{\mathrm{c}}$ & 50.160 & 91.587 & 255.547 & 51.052 & 99.762 & 259.405 & 8.9 \\
\hline Daily accessibility ${ }^{\mathrm{d}}$ & 1.05 & 4.27 & 8.69 & 1.07 & 5.13 & 11.54 & 20.0 \\
\hline minutes & \multirow{4}{*}{\multicolumn{7}{|c|}{$\begin{array}{l}{ }^{\mathrm{e}} \text { minimum value } \\
{ }^{\mathrm{f}} \text { mean value } \\
{ }_{\mathrm{g}} \text { maximum value } \\
{ }_{\mathrm{h}}\end{array}$}} \\
\hline & & & & & & & \\
\hline${ }^{\mathrm{c}}$ inhab/minutes $\times 10^{3}$ & & & & & & & \\
\hline${ }^{\mathrm{d}}$ million inhab & & & & & & & \\
\hline
\end{tabular}

Results show that change rates depend on the indicator chosen, ranging from a maximum $20.0 \%$ for the daily accessibility indicator to a $7.5 \%$ for the network accessibility indicator. For example, in terms of the location indicator, mean weighted average travel times are reduced from $640 \mathrm{~min}$ in 1992 to $589 \mathrm{~min}$ in 2004 (i.e. a $7.9 \%$ reduction).

It can be noted that the ratios between the percentages of change remain similar to the ones resulting for the road mode (see Table 1): daily accessibility shows above double the percentage change of location, network efficiency and population potential indicators, which show similar percentage change.

The comparison of Table 1 and 2 values also shows that the overall accessibility levels are better for the road than for the rail mode, both in 1992 and 2004, for all accessibility indicators: in terms of the location indicator mean weighted average travel times are 589 min by rail, against a 350 min value by road.

Figures 5 to 8 map differences in rail mode accessibility values between 1992 and 2004, in percentage change of 1992 values, for the location, network efficiency, population potential and daily accessibility indicators, respectively. In all cases, the resulting overall pattern is similar: the Madrid-Barcelona corridor benefits from the opening of the Madrid-Lleida HSR, along with some improvements of the Mediterranean (Euromed) line. Therefore, this corridor shows the higher percentage improvements, with values over $20 \%$.

The effects of this HSR also benefit indirectly the Madrid- Seville corridor, as it connects it with the second larger city in Spain after Madrid: Barcelona. Both the aforementioned corridors enjoyed above-average accessibility values in 1992, which signals an increase in regional disparities, as will be discussed in section 4.3. 
Figure 5. Changes in location accessibility indicator 1992-2004. Rail mode

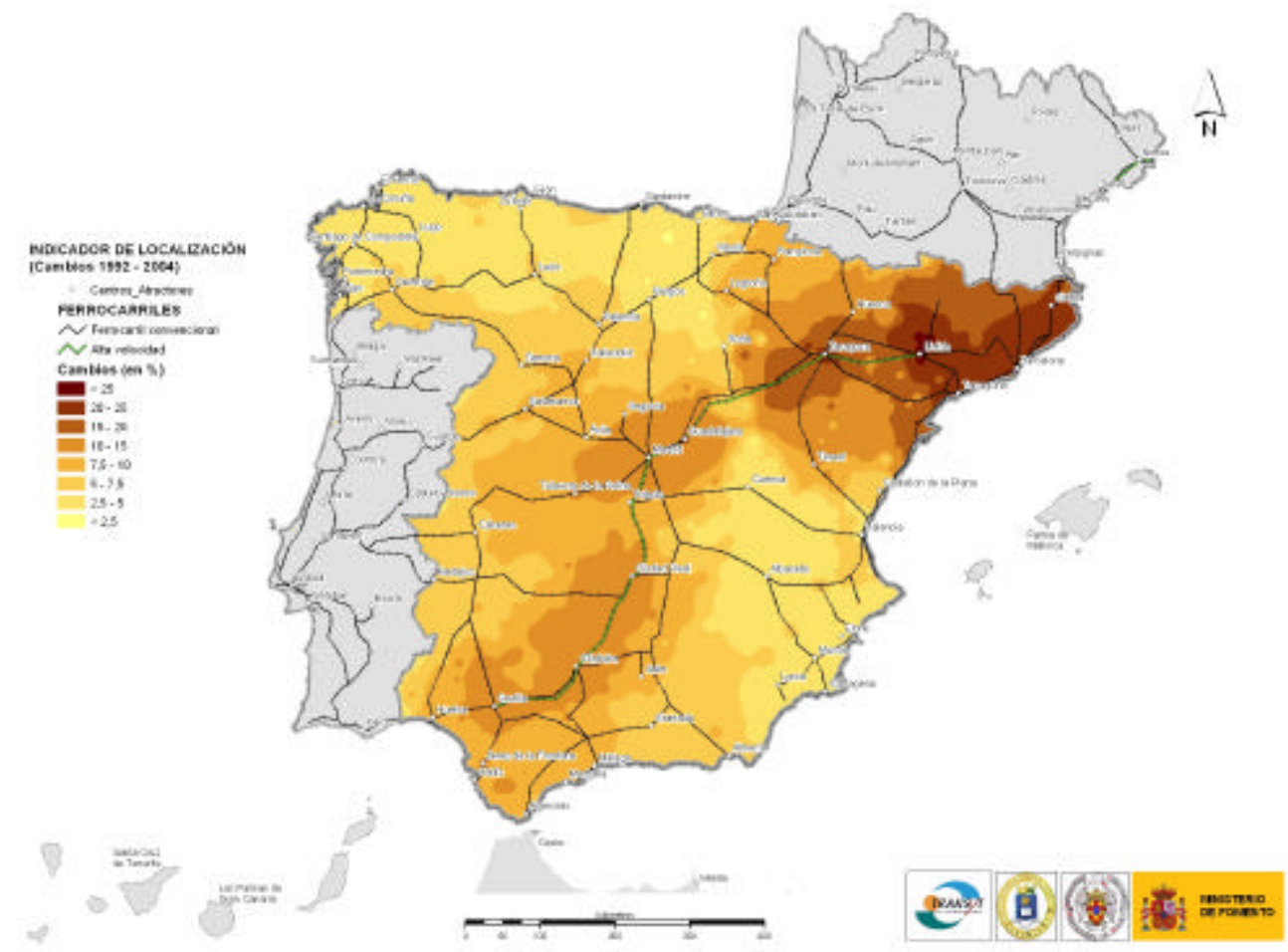

Figure 6. Changes in network efficiency accessibility indicator 1992-2004. Rail mode

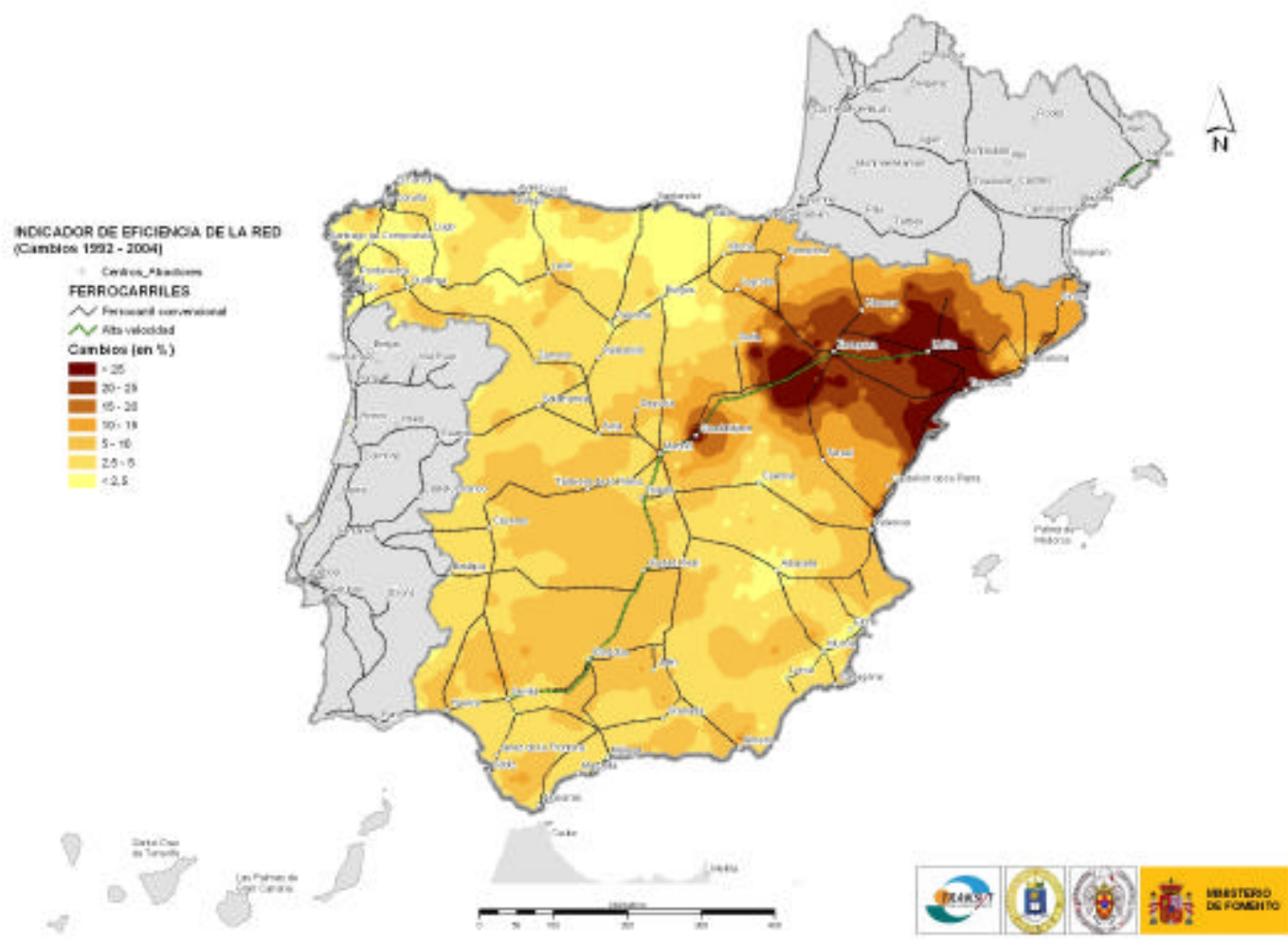


Figure 7. Changes in population potential accessibility indicator 1992-2004. Rail mode

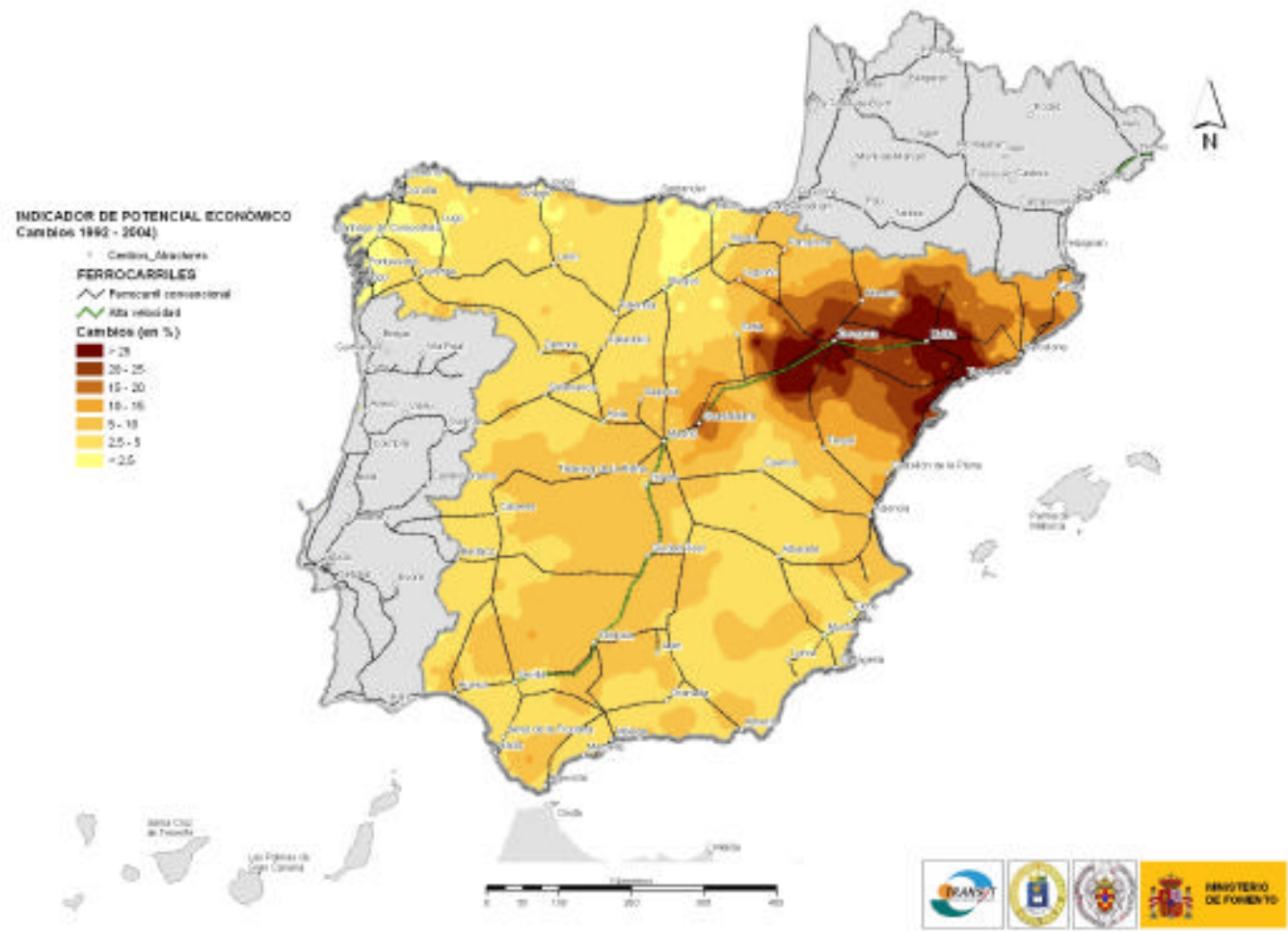

Figure 8. Changes in daily accessibility indicator 1992-2004. Rail mode

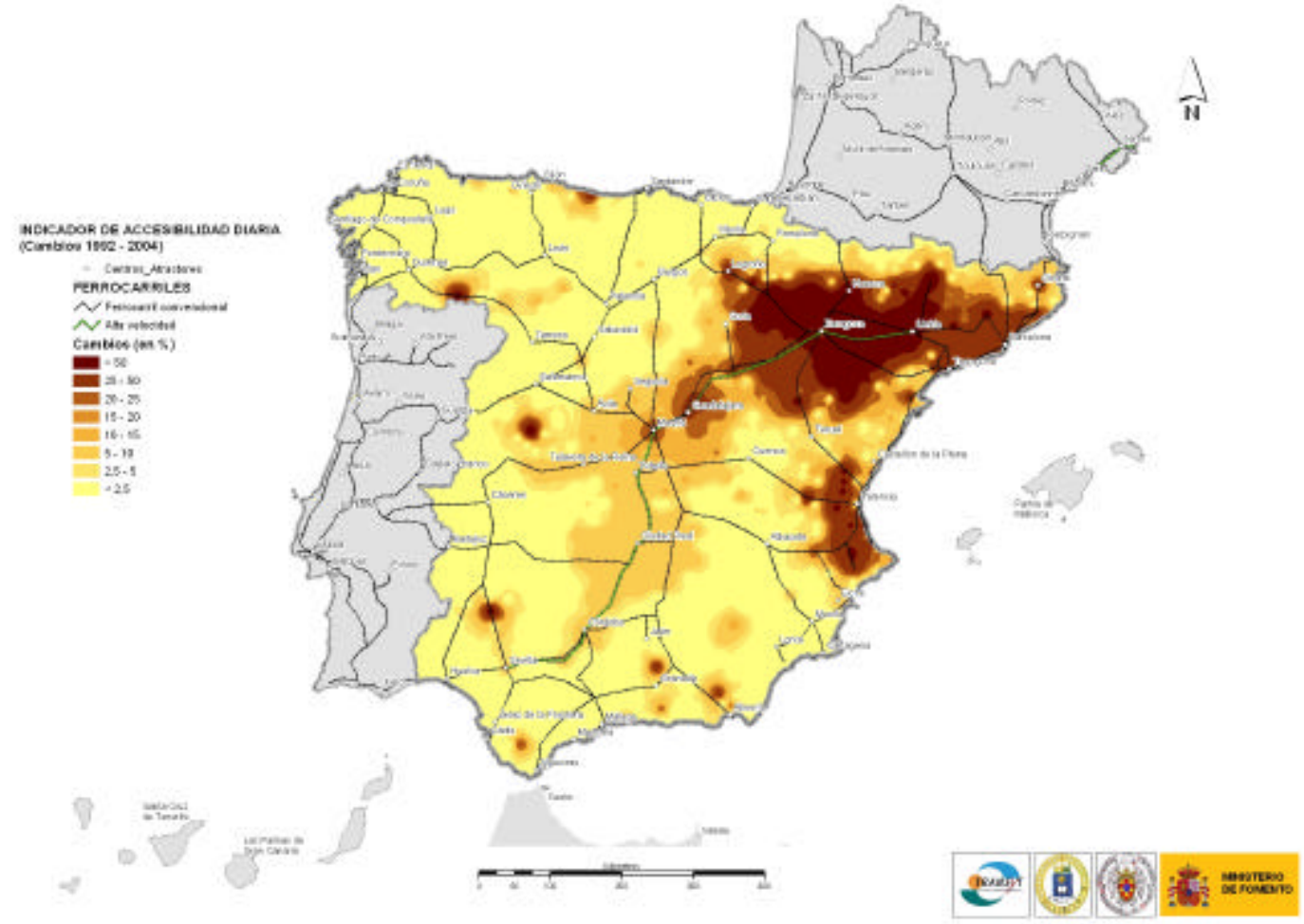




\subsection{Cohesion/Inequality indices}

\subsubsection{Static analysis}

\subsubsection{Differences depending on the accessibility indicator}

The results included in Table 3 clearly show that, both for road and rail modes, the choice of the accessibility indicator is a key factor influencing the conclusions taken. For both indices, daily and potential indicators show significantly higher regional disparities than location and network efficiency indicators. This is consistent with previous similar studies (Schürmann et al, 1997, Martín et al, 2004).

Table 3: Inequality indices of selected accessibility indicators, 1992, 2004 and \% change, Road and rail modes

\begin{tabular}{lrrrrrr}
\hline & \multicolumn{3}{c}{ Road } & \multicolumn{3}{c}{ Rail } \\
\hline $\begin{array}{l}\text { Inequality index } \\
\text { /Accessibility indicator }\end{array}$ & 1992 & 2004 & $\begin{array}{c}\% \\
\text { change }\end{array}$ & 1992 & 2004 & $\begin{array}{c}\% \\
\text { change }\end{array}$ \\
\hline Variation coefficient & & & & & & \\
Location & 15.328 & 13.694 & -10.659 & 15.940 & 17.985 & 12.828 \\
Network efficiency & 7.884 & 6.763 & -14.210 & 18.252 & 20.494 & 12.283 \\
Population potential & 34.588 & 33.262 & -3.834 & 38.433 & 39.221 & 2.050 \\
Daily accessibility & 36.995 & 32.941 & -10.958 & 55.461 & 58.702 & 5.843 \\
GINI index & & & & & & \\
Location & 0.096 & 0.087 & -9.300 & 0.107 & 0.119 & 10.644 \\
Network efficiency & 0.078 & 0.070 & -9.512 & 0.186 & 0.188 & 1.294 \\
Population potential & 0.277 & 0.237 & -14.379 & 0.299 & 0.293 & -1.741 \\
Daily accessibility & 0.253 & 0.229 & -9.418 & 0.332 & 0.361 & 8.710 \\
\hline
\end{tabular}

In particular, for the road mode, the coefficient of variation in 1992 ranges between a $37 \%$ for the daily indicator to only an $8 \%$ for the network efficiency indicator. For the rail mode, the resulting interval is even larger: 59\% and 18\%, for the daily and location indicators, respectively.

\subsubsection{Comparison between modes}

Comparing now between road and rail modes, results show that, for all indices and accessibility indicators, accessibility by road was in 1992 more equally distributed than by rail, in accordance with previous studies (Bruinsma y Rietveld, 1993; Gutiérrez et al, 1998). The following reasons appear as the main responsible for these differences:

- first, in 1992 the High Capacity road network was far more developed than the HSR network. While the first covered most of the Iberian Peninsula, with over $5,800 \mathrm{~km}$, the latter only included the Madrid-Seville line, with approximately $450 \mathrm{~km}$.

- second, independently from the aforementioned level of development of each network, the density of "access nodes" (i.e. junctions) in the road mode is significantly higher than for the rail mode, where access is only possible at the stations. 
- finally, differences between average speeds are much larger for rail mode (i.e. high speed vs. conventional rail speed) than for road mode (i.e. highway speed vs. conventional roads speed). Therefore, the implementation of a single HSR line may induce higher spatial polarising effects than a new highway.

Thus, the "intrinsic features" of each mode are the driving forces behind this roadrail differences in spatial cohesion effects. New infrastructure investments have therefore a limited potential to reduce these differences between both modes. Hence, it is not surprising to verify that the relative situation between both modes has not changed in 2004. Road and rail infrastructure implemented in the period 1992-2004 have not changed the final picture: accessibility by road is more equally distributed than by rail

\subsubsection{Dynamic analysis: cohesion effects 1992-2004}

\subsubsection{Road mode}

First, for this dynamic analysis, it is carried out a comparison of the values of the inequality indices in 1992 and 2004. For this purpose, Table 3 includes a row computing percentage changes (in terms of 1992 values). Results show that for all accessibility indicators, cohesion has slightly improved. Indeed, both the resulting variation coefficient and Gini index have dropped in a percentage ranging from $-3.8 \%$ and $-14.4 \%$, depending on the accessibility indicator chosen.

In addition, this analysis is complemented with the values of the correlation coefficients included in Table 4. Starting with the Spearman correlation coefficient, the closeness to one of all values (higher than 0,940), indicates that the development of the road network results in a little impact on the positions of the regions in the rank order of accessibility. Finally, the negative sign of the relative and absolute correlation coefficients confirms the conclusions taken from the analysis of the variation coefficient and the Gini index: a reduction of regional disparities.

Table 4: Correlation coefficients 1992 vs. 2004. Road and rail modes

\begin{tabular}{lrr}
\hline & Road & \multicolumn{1}{l}{ Rail } \\
\hline Spearman rank correlation coefficient & & \\
Location & 0.985 & 0.952 \\
Network efficiency & 0.943 & 0.922 \\
Population potential & 0.997 & 0.959 \\
Daily accessibility & 0.949 & 0.896 \\
Correlation level vs. absolute change & & \\
Location & -0.727 & -0.036 \\
Network efficiency & -0.609 & -0.106 \\
Population potential & -0.098 & 0.206 \\
Daily accessibility & -0.221 & 0.238 \\
Correlation level vs. relative change & & \\
Location & -0.610 & 0.075 \\
Network efficiency & -0.457 & 0.166 \\
Population potential & -0.351 & 0.048 \\
Daily accessibility & -0.488 & -0.023 \\
\hline
\end{tabular}


Therefore, it can be stated that, for the road mode, cohesion has slightly increased. This conclusion is coherent with the expected impacts from the changes of the road network in the 1992-2004 period. Investments were mainly aimed to close the remaining links to connect peripheral regions, like Galicia, to the High Capacity network. In addition, the aforementioned investments contributed to the completion of a denser grid, via the construction of cross and longitudinal links which have reduced the pronounced radial feature of the Spanish road network.

\subsubsection{Rail mode}

Table 3 includes the indices obtained for the rail mode, included in Table 3. Resulting values show that cohesion has slightly decreased in the period 1992-2004, in seven out of the eight computed indices.

However, conclusions deriving from the analysis of results included in Table 4 are not clear, at least at a first look. In all cases, the Spearman correlation coefficients result in close to one values, (although slightly lower than for the road mode), therefore showing that there have been no significant shifts in the rank positions. The interpretation of the results of the correlation coefficients between change and level is more complex: they signal both cohesion (i.e. negative sign of the coefficient) and polarising (i.e. positive sign) effects. Notwithstanding that the resulting balance is more inclined towards polarisation effects (five out of eight coefficients are positive), caution should be paid before making categorical asserts about increasing or decreasing disparities on the basis of the aforementioned coefficients.

The observed tendency of HSR to introduce polarising effects is in accordance with previous similar studie s at a national scale (Gutiérrez, 2001; Martín et al, 2004) and at an EU scale (Bruinsma y Rietveld, 1993, 1998; Vickerman et al, 1999; Gutiérrez y Urbano, 1996).

It can also be stated that results heavily depend on the cohesion index used (in line with Bröcker et al, 2004), therefore a set of indices should be used and their results analysed complementary.

\section{Conclusions}

This paper concludes that regional cohesion effects derived from the development of transport networks in Spain in the period 1992-2004 have been equitable for the road mode while polarising for the rail mode. HSR tends to improve the relative position of large urban agglomerations, most of them already enjoying above-average accessibility levels, therefore increasing regional disparities in accessibility. This conclusion is consistent with previous studies, both at national and EU scales (Bruinsma and Rietveld, 1993; Gutiérrez, 2001;Vickermann et al, 1999), which alert of the "polarising proneness" of HSR lines.

In addition, the paper also stresses that measuring cohesion effects should be done with caution, as there are many possible sources of bias in the process. First, the choice of the cohesion index: depending on the index chosen, the conclusions may be even opposite. Therefore, the best option is to calculate a set of indicators and integrate their results. Conclusions relying on only one indicator should be avoided (Bröcker et al, 2004). 
Second, the selection of the accessibility indicator: in terms of the four selected indicators for this study, potential and daily accessibility indicators tend to show less equitable distributions than location and network efficiency indicators.

Third, the geographical scale: it may happen that the results obtained are different depending on where we put the geographic boundaries of the study. At EU scale, a new infrastructure connecting a peripheral Member State, e.g. Spain, with the EU core may increase cohesion. The same infrastructure may have polarising effects if we move to a national level and investigate how disparities change within the national boundaries (Gutiérrez, 2001, Martín et al, 2004). The same problems are faced if the scale is changed to the corridor level.

In summary, the lesson learned is that it is far from obvious to assert that improved transport infrastructure brings improved cohesion. More research is needed to develop a common approach to measuring regional cohesion effects of transport infrastructure investments.

\section{Acknowledgments:}

Support from Ministerio de Fomento (Transport Research Aids), comments from J.Gutiérrez, and assistance in computing and mapping accessibility values from G.Gómez are gratefully acknowledged.

\section{References}

Beuthe, M. (2002) Transport Evaluation Methods: from Cost-benefit Analysis to Multicriteria Analysis and the Decision Framework. In Project and Policy Evaluation in Transport (Giorgi, L., Pearman, A. (eds.)) Ashgate, London.

Bökeman, D., Hackl, R., Kramar, H. (1997) Socio-Economic Indicators Model and Report.SASI Deliverable D4. Report to the European Comission. Wien: Institut für Stadt-und Regionalforschung, Technische Universität Wien.

Bröcker, J., Meyer, J., Schneekloth, N., Schürmann, C., Spiekermann, K., Wegener, M. (2004) Modelling the Socio-Economic and Spatial Impacts of EU Transport Policy. IASON Deliverable 3. Funded by 5th Framework RTD Programme. Kiel/Dortmund: ChristianAlbreschts- Universität Kiel/Institüt für Raumplanung, Universität Dortmund.

Bruinsma, F., Rietveld, P. (1993) Urban agglomerations in European infrastructure networks Urban Studies 30, p 919-934.

Bruinsma, F., Rietveld, P. (1998) The accessibility of european cities. Environment and Planning A, vol 30, pp 499-521.

European Commision (2004) A new partnership for cohesion :convergence competitiveness cooperation. Third report on economic and social cohesion. Office for Official Publications of the European Communities, Luxembourg.

European Commission (2004a) Decision No 884/2004/EC of the European Parliament and of the Council amending Decision No 1692/96/EC on 21 April 2004 on Community guidelines for the development of the trans-European transport network

European Commission (1999) ESDP European Spatial Development Perspective: Towards balanced and sustainable development of the territory of the European Union, Prepared by the Committee of Spatial Development, Luxembourg.

Geurs K.T., van Wee, B., (2004) Accessibility evaluation of land-use and transport strategies: review and research directions. Journal of Transport Geography, vol 12, pp 127-140. 
Geurs K.T., Ritsema Van Eck J.R. (2003) Evaluation of accessibility impacts of land-use scenarios: the implications of job competition, land-use, and infrastructure development for the Netherlands, Environment and Planning B, vol 30, pp 69-87.

Geurs K.T., Ritsema Van Eck J.R. (2001) Accessibility measures: review and applications. Evaluation of accessibility impacts of land-use transportation scenarios, and related social and economic impacts. RIVM Rapport 408505006. National Institute of Public Health and the Environment. RIVM, Bilthoven

Grant-Muller S.M., Mackie P.J., Nellthorp J., Pearman A.D. (2001), Economic Apprasal of European Transport Projects- The State of the Art Revisited. Transport Reviews 21(2), p237261

Gutiérrez, J. y Urbano, P. (1996) Accessibility in the European Union: the impact of the transEuropean road network. Journal of Transport Geography, vol. 4, No 1, pp- 15-25.

Gutiérrez, J., (2001) Location, economic potential and daily accessibility: an analysis of the accessibility impact of the high-speed line Madrid-Barcelona-French Border Journal of Transport Geography 9 (2001), 229-242.

Gutiérrez, J., Conzález, R., y Gómez, G. (1996). The European high -speed train network. Predicted effects on accessibility patterns. Journal of Transport Geography, vol 4, Nº, pp. $227-$ 238.

Gutiérrez, J., Monzón, A., Piñero, J.M. (1998) Accessibility, network efficiency, and transport infrastructure planning Environment and Planning A, vol 30, pp 1337-1350.

Halden, D. (2003) Accessibility analysis: concepts and their application to transport policy, programme and project evaluation. In Pearman, A., Mackie, P., and Nellthorp, J. (eds.) Transport Projects, Programmes and Policies: Evaluation needs and capabilities. Ashgate, Hampshire.

Hansen W.G. (1959) How accessibility shapes land-use. Journal of the American Institute of Planners 25, 73-76.

Hayashi, Y., Morisugi, H. (2000) International comparison of background concept and methodology of transportation project appraisal. Transport Policy, vol 7, pp 73-88.

Lutter, H., Pütz, T., Spangenberg, T., (1992) Accessibility and Peripherality of Community Regions : the Role of Road, Long-Distance Railways and Airport Networks. Report to the European Comission DG XVII. Bundesforschungsanstalt für Landeskunde und Raumordnung, Bonn.

Mackie, P. and Nellthorp (2003) Transport Appraisal in a Policy context. In Pearman, A., Mackie, P., and Nellthorp, J. (eds.) Transport Projects, Programmes and Policies: Evaluation needs and capabilities. Ashgate, Hampshire.

Martín, J.C., Gutiérrez, J. y Román, C. (2004) Data Envelopment Análisis (DEA) Index to measure the accessibility impacts of new infrastructure investments: the case of the High-Speed Train Corridor Madrid-Barcelona-French border. Regional Studies, vol 38, pp 697-712.

Ministry for Development (2004) Infrastructures and Transport Strategic Plan (PEIT), Proposal Document, State Secretary for Infrastructures and Planning, Directorate General for Planning and Territorial Coordination, Madrid.

Official Journal of the European Union (2004) Treaty Establishing a Constitution for Europe, Official Journal of the European Union, C310, 16.12.2004.

Schürmann, C., Spiekermann, K., Wegener, M. (1997) Accessibility indicators, Berichte aus dem Institüt für Raumplanung 39, IRPUD, Dortmund 
Simmonds, D. (1998) Accessibility as a criterion in policy and project appraisal. Unpublished Report for the Department of the Environment, Transport and the Regions, David Simmonds Consultancy, University of Leeds, MVA, Oxford Brooks University.

Talen, E. (1998) Visualizing equity maps for planners Journal of the American Planning Association, vol 64, issue 1, pp-22-49.

Vickerman, R.W., Spiekermann, K., Wegener, M. (1999) Accessibility and economic development in Europe. Regional Studies, 33, pp 1-5.

Wegener, M., Eskelinnen, H., Fürst, F., Schürmann, C., Spiekermann, K., (2000). Indicators of Geographical Position .Final Report of the Working Group "Geographical Position" of the Study Programme on European Spatial Planning. Dortmund, IRPUD. 